\title{
Clinical Characteristics and Outcome of Bloodstream Infections in HIV-Infected Patients with Cancer and Febrile Neutropenia: A Case-Control Study
}

\author{
Pedro Puerta-Alcalde (D) · Juan Ambrosioni · Mariana Chumbita • Marta Hernández-Meneses • \\ Nicole Garcia-Pouton · Celia Cardozo • Estela Moreno-García · Francesc Marco • Josep Mensa • \\ Montserrat Rovira · Jordi Esteve · Jose A. Martínez · Felipe García · Josep Mallolas • \\ Alex Soriano · José M. Miró · Carolina Garcia-Vidal
}

Received: January 28, 2021 / Accepted: March 27, 2021 / Published online: April 11, 2021

(C) The Author(s) 2021

\section{ABSTRACT}

Introduction: We aimed to compare the clinical characteristics and outcomes of bloodstream infections (BSI) in cancer patients presenting febrile neutropenia with and without HIV infection, and analyze the prognostic factors for mortality.

Methods: BSI episodes in febrile neutropenic patients following chemotherapy were prospectively collected (1997-2018). A case (HIV-infected)-control (non-HIV-infected) subanalysis was performed (1:2 ratio), matching

José M. Miró and Carolina Garcia-Vidal have equivalent merits as senior authors.

Supplementary Information The online version contains supplementary material available at https:// doi.org/10.1007/s40121-021-00445-3.

P. Puerta-Alcalde $(\varangle) \cdot$ J. Ambrosioni $(\bowtie)$.

M. Chumbita · M. Hernández-Meneses .

N. Garcia-Pouton · C. Cardozo · E. Moreno-García

J. Mensa · J. A. Martínez · F. García · J. Mallolas .

A. Soriano · J. M. Miró · C. Garcia-Vidal

Infectious Diseases Department, Hospital Clinic-

IDIBAPS, Carrer de Villarroel 170, 08036 Barcelona, Spain

e-mail: pedro.puerta84@gmail.comJ. Ambrosioni

e-mail: jambrosioni@intramed.net

F. Marco

Microbiology Department, Centre Diagnòstic

Biomèdic, Hospital Clinic, Barcelona, Spain patients by age, gender, baseline disease, and etiological microorganism.

Results: From 1755 BSI episodes in neutropenic cancer patients, $60(3.4 \%)$ occurred in those with HIV. HIV characteristics: $51.7 \%$ were men who have sex with men; $58.3 \%$ had $<200$ CD4; $51.7 \%$ had a detectable HIV-1 RNA viral load before the BSI episode; $70.0 \%$ met AIDS-defining criteria; and 93.3\% were on antiretroviral therapy, with a protease inhibitor-based regimen being the most common (53.0\%). HIV-infected patients were younger, more frequently male and more commonly presenting chronic liver disease $(p<0.001$ for all). BSI due to Enterococcus spp. was significantly more frequent among patients with HIV $(p=0.017)$ with no differences in other pathogens. HIV-infected patients with cancer presented with shock more frequently $(p=0.014)$ and had higher mortality

\section{F. Marco}

ISGlobal, Hospital Clinic, University of Barcelona, Barcelona, Spain

M. Rovira · J. Esteve

Hematology Department, Hospital Clinic-IDIBAPS, Barcelona, Spain

M. Rovira · J. Esteve · J. A. Martínez · F. García J. Mallolas · A. Soriano · J. M. Miró · C. Garcia-Vidal University of Barcelona, Barcelona, Spain 
(31.7\% vs. $18.1 \%, p=0.008)$. In the case-control analysis, cases (HIV-infected) had chronic liver disease $(p=0.003)$ more frequently, whereas acute leukemia $(p=0.013)$ and hematopoietic stem-cell transplant $(p=0.023)$ were more common among controls. There was a non-significant trend for cases to have higher mortality $(p=0.084)$. However, in multivariate analysis, HIV infection was not associated with mortality $(p=0.196)$.

Conclusion: HIV-infected patients with cancer developing febrile neutropenia and BSI have different epidemiological and clinical profiles, and experience higher mortality. However, HIV infection by itself was not associated with mortality.

Keywords: Bacteremia; HIV; Multidrug resistance; Neutropenia

\section{Key Summary Points}

\section{Why carry out this study?}

Patients with HIV who develop cancer face intrinsic immunosuppression in addition to the neutropenia and toxicity associated with chemotherapy.

We aimed to compare the clinical characteristics and outcomes of BSI in febrile neutropenic cancer patients with and without HIV infection.

BSI characteristics in cancer patients with HIV may be different and HIV can be associated with increased mortality.

\section{What was learned from the study?}

HIV-infected patients with cancer, febrile neutropenia, and BSI have different clinical and etiological profiles from nonHIV-infected patients.

HIV cancer patients present with shock more frequently and have higher mortality.

However, in the case-control cohort, HIV was not an independent prognostic factor for mortality.

\section{DIGITAL FEATURES}

This article is published with digital features, including a summary slide, to facilitate understanding of the article. To view digital features for this article go to https://doi.org/10.6084/ m9.figshare.14319479.

\section{INTRODUCTION}

Bloodstream infections (BSI) are the most frequent infectious complications in patients with post-chemotherapy febrile neutropenia, associated with high morbidity and mortality $[1,2]$. Antibiotic treatment is challenging due to the rise in multidrug-resistant organisms, and inappropriate empirical treatment is associated with an increase in mortality [3-6].

Patients with human immunodeficiency virus (HIV) infection not undergoing antiretroviral therapy (ART) develop AIDS and, in many cases, AIDS-defining tumors $[7,8]$. With the introduction of combined ART, however, HIV infection has become a chronic disease, and the number of individuals living with HIV continues to increase [9-11]. This has in turn been associated with an increased risk of non-AIDSdefining tumors [12-14]. Incidence of, and even mortality from, these non-AIDS-defining tumors appear to be higher in patients with HIV than in the general population $[15,16]$.

Patients with HIV who develop cancer, especially those with a lower CD4 level, have intrinsic immunosuppression, which is added to the neutropenia and toxicity associated with chemotherapy [13-15]. Moreover, some patients receive ART regimens having relevant drug-drug interactions that may complicate chemotherapy administration and lead to additional complications. Information concerning characteristics of BSI in patients with HIV and cancer who develop febrile neutropenia following chemotherapy is absent, and no specific recommendations are available for these patients upon febrile neutropenia onset.

We aimed to compare the clinical characteristics and outcomes of BSI in febrile neutropenic cancer patients with and without HIV 
infection, and to analyze prognostic factors for mortality.

\section{METHODS}

\section{Setting and Data Collection}

This study was performed at the Hospital Clinic in Barcelona (Spain), a 700-bed university center providing specialized and broad medical, surgical, and intensive care for an urban population of 500,000 people. The HIV Unit of the Hospital Clinic has currently close to $6000 \mathrm{HIV}$ positive patients on active follow-up.

Since 1997, data on vital signs, laboratory and microbiological tests, complementary imaging explorations and administered treatment have been computerized. Concurrently, our institution has conducted a blood culture surveillance program identifying and monitoring all patients with bacteremia, as well as a parallel program that follow all patients with HIV. The collected data have been entered into specific databases designed for these programs.

\section{Study Population and Design}

For this study, we identified all episodes of febrile neutropenia following chemotherapy occurring in patients with cancer and HIV from January 1997 to March 2018.

The following data were obtained from all patients: age, gender, comorbidities, treatment with antibiotics or steroids in the previous month, recent hospitalization (within the last month), current administration of antibiotic treatment, neutrophil count, CD4 lymphocyte count, HIV viral load, microbiological isolates and their susceptibility profile, empirical antibiotic treatment, definitive antibiotic therapy, and 30-day mortality. A case (HIV-infected)-control (non-HIV-infected) sub-analysis was performed with a ratio of 1:2, matching patients for age, gender, baseline disease, and etiological microorganism. Wherever feasible, the match with the closest year of BSI was chosen.
This study was performed in accordance with the Helsinki Declaration, and followed privacy laws regarding active anonymity. This study was approved by the Ethics Committee Board of our institution (Comité de Ética de la Investigación con medicamentos, Hospital Clínic de Barcelona) with the following approval verdict: $\mathrm{HCB} / 2019 / 0764$. Informed consent was waived due to the retrospective nature of the study.

\section{Definitions}

Patients with febrile neutropenia were defined as those who had a single oral temperature measurement of $>38.3^{\circ} \mathrm{C}$ or of $>38.0^{\circ} \mathrm{C}$ sustained over a 1-h period, and an absolute neutrophil count of $<500$ cells $/ \mathrm{mm}^{3}$ [17]. Prior antibiotic therapy was defined as the use of any antimicrobial agent for $\geq 3$ days during the month prior to the occurrence of the bacteremia episode [18]. Since 1995, according to the protocols of our hospital, patients with expected neutropenia over 10 days received prophylaxis with fluoroquinolone [19]. Breakthrough bacteremia was defined as a BSI occurring despite the patient receiving antibiotic treatment that was active against the isolated pathogen. Chronic renal failure was defined as an abnormality of kidney structure or function, present for $>3$ months, with a decreased glomerular filtration rate $(<60 \mathrm{ml} / \mathrm{min} / 1.73$ $\mathrm{m}^{2}$ ). For HIV viral load and CD4 cell count, the most recent value available before the BSI was considered. Corticosteroid therapy was defined as the use of a dose $\geq 20 \mathrm{mg}$ of daily prednisone or equivalent. Nosocomial infection was defined as that occurring $48 \mathrm{~h}$ after hospital admission. Healthcare-associated infection was defined when the subject met at least one of the following criteria: recent hospitalization (within the last 30 days), admission from longterm care facility, and chronic hemodialysis or intravenous treatment during the previous month. The remaining patients were classified as community-acquired [19]. BSI was considered to be from an unknown or endogenous source where no other source was identified. Catheterrelated infections were defined as: (1) at least one positive blood culture and a positive semi- 
quantitative catheter-tip culture with growth of the same microorganism, and (2) a positive paired central and peripheral blood culture that grew the same microorganism; i.e., the former blood culture was positive $\geq 2 \mathrm{~h}$ earlier, or the site of insertion of vascular access showed signs of infection [19, 20]. Overall mortality was defined as death by any cause within the first 30 days of BSI onset.

\section{Microbiological Methods}

Blood samples were processed using the BACTEC 9240 system or BACTEC FX system (Becton-Dickinson Microbiology Systems), with an incubation period of 5 days. Isolates were identified by standard techniques. Antimicrobial susceptibility testing was performed by using a microdilution system (Microscan WalkAway; Dade Behring, West Sacramento, CA, USA, or Phoenix system; Becton Dickinson, Franklin Lakes, NJ, USA) or the Etest (Biodisk: Solna, Sweden/bioMérieux, Mercy l'Etoile, France). Current Clinical and Laboratory Standards Institute (CLSI) or the European Committee on Antimicrobial Susceptibility Testing (EUCAST) breakpoints for each year were used to define susceptibility or resistance to these antimicrobial agents, and intermediate susceptibility was considered as resistance [6]. Viral load limit of detection varied over time. A cut-off of $<50$ copies/mL was considered as undetectable.

\section{Statistical Analysis}

Categorical variables were described by counts and percentages, whereas continuous variables were expressed as means and standard deviations (SD) or medians and interquartile ranges (IQRs). Pearson's chi-squared test and the Mann-Whitney $U$ test or Student's $t$ test were used to compare the distribution of categorical and continuous variables, respectively. Chisquared for trend was used to compare the HIV characteristics over time. Factors associated with 30-day mortality in the case-control cohort were assessed using logistic regression models. All analyses were performed with SPSS software (v.18.0; SPSS, Chicago, IL, USA).

\section{RESULTS}

Between 1997 and 2018, a total of 1755 episodes of bacteremia were documented in patients with neutropenia following chemotherapy. Of these, $60(3.4 \%)$ episodes were identified in patients with HIV infection (Fig. 1).

\section{Characteristics of HIV-Infected Patients Regarding their Baseline Disease}

Table 1 details the characteristics of patients with HIV in relation to baseline disease, and compares these characteristics in terms of patient mortality as a result of the bacteremia. The most prevalent risk behavior was that of men who have sex with men $(46.7 \%), 58.3 \%$ had $<200 \mathrm{CD} 4$, and $70 \%$ met AIDS-defining criteria. Overall, $38.3 \%$ had a positive HIV-1 RNA viral load prior to the bacteremia episode, with a mean viral load of 484,982 copies/mL (SD 934,076). Most patients (91.4\%) were on ART at the time of the BSI; a protease inhibitorbased ART was the most common regimen $(53.0 \%)$ and median time since initiation of treatment was 23 months (IQR 4-48). ART regimens including a nucleoside/nucleotide reverse transcriptase inhibitors (NRTI) were more prevalent among those who survived $(p=0.019)$. Additionally, $14 \quad(25.0 \%)$ patients had hepatitis C virus (HCV), 12 (21.4\%) hepatitis B virus (HBV) and 6 (10.0\%) both.

Table 2 displays the evolution of HIV characteristics over time. Throughout the study period, no changes were observed in risk behaviors, CD4 counts, and rates of patients receiving ART or meeting AIDS criteria. However, the percentage of patients with detectable viral load decreased over time $(p=0.046)$, and the percentage of patients receiving an integrase inhibitor increased $(p<0.001)$.

\section{Comparison of Bacteremia Episodes in Cancer Patients with and Without HIV Infection}

Table 3 compares bacteremia episodes according to the patient's HIV status. Patients with 


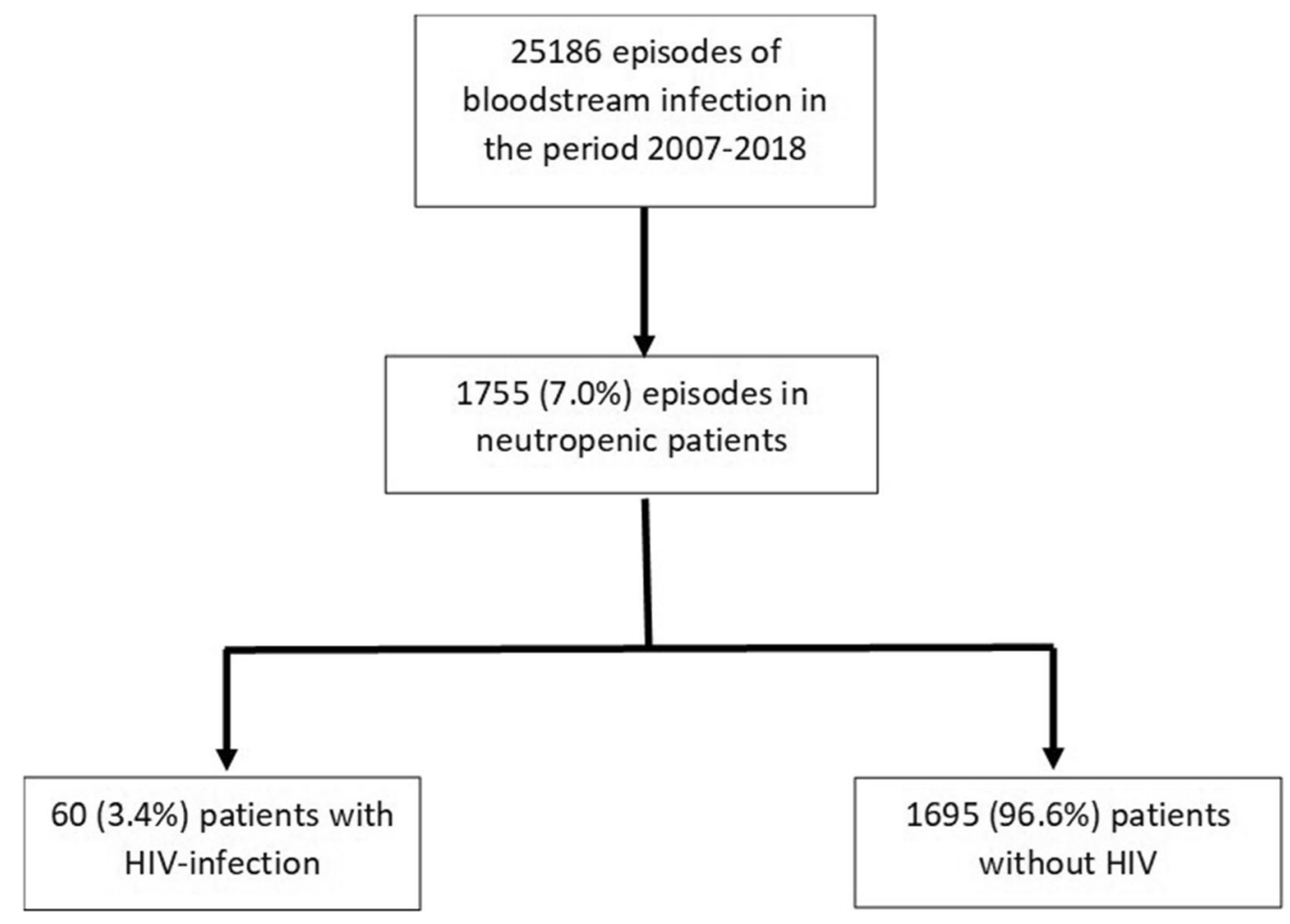

Fig. 1 Flowchart of bloodstream infection episodes

HIV were younger, more frequently male, and more commonly presented with chronic liver disease $(p<0.001$ for all). Conversely, HIV-infected patients underwent significantly fewer hematopoietic stem cell transplantations (HSCT) $(p<0.001)$.

There was no difference in the source of bacteremia. BSI due to Enterococcus spp. was significantly more frequent among patients with HIV $(p=0.017)$, with no differences in other pathogens. Finally, HIV-infected patients presented with shock and required intensive care unit (ICU) admission more frequently $(p=0.014$ and $p=0.006$, respectively) and experienced higher mortality $(31.7 \%$ vs. $18.1 \%$, $p=0.008)$.

Supplementary Table 1 shows the changes over time in the main causative agents and their antimicrobial susceptibility.

\section{Prognostic Factors in HIV-Infected Patients with Cancer}

An analysis of risk factors for mortality was performed by selecting only those patients with HIV-infection and cancer. In the univariate study, diabetes mellitus $(p=0.031)$, abdominal source $(p=0.028)$, shock $(p=0.026)$, and $E$. coli BSI $(p=0.023)$ were associated with higher mortality. However, ART containing an NRTI $(p=0.019)$ and catheter-related bacteremia $(p<0.001)$ were associated with lower mortality. Patients with HIV infection and a detectable viral load showed a trend to higher mortality $(43.5 \%$ vs. $24.3 \%, p=0.121)$, while those receiving ART showed a trend to have lower mortality (28.3\% vs. $60.0 \%, p=0.167)$.

In multivariate analysis, factors independently associated with increased mortality in patients with HIV-infection and cancer were diabetes mellitus (OR 23.962, 95\% CI 1.882-305.102) and shock (OR 9.918, 95\% CI 2.093-46.998). 
Table 1 Characteristics of patients with HIV regarding their baseline disease

\begin{tabular}{|c|c|c|c|c|}
\hline & Episodes $n=60(\%)$ & Alive $n=41(\%)$ & Dead $n=19(\%)$ & $p$ value \\
\hline \multicolumn{5}{|l|}{ Risk behavior } \\
\hline MSM & $28(46.7)$ & $18(43.9)$ & $10(52.6)$ & 0.528 \\
\hline Heterosexual & $18(30.0)$ & $13(31.7)$ & $5(26.3)$ & 0.672 \\
\hline IVDU & $9(15.0)$ & $5(12.2)$ & $4(21.1)$ & 0.445 \\
\hline Unknown & $5(8.3)$ & $5(12.2)$ & $0(0)$ & 0.168 \\
\hline \multicolumn{5}{|c|}{ Prior CD4 count } \\
\hline$<100$ & $21(35.0)$ & $14(34.1)$ & $7(36.8)$ & 0.839 \\
\hline $101-200$ & $14(23.3)$ & $8(19.5)$ & $6(31.6)$ & 0.304 \\
\hline $201-350$ & $8(13.3)$ & $7(17.1)$ & $1(5.3)$ & 0.416 \\
\hline$>350$ & $10(16.7)$ & $7(17.1)$ & $3(15.8)$ & 1.000 \\
\hline NA & $7(11.7)$ & $5(19.2)$ & $2(16.7)$ & 1.000 \\
\hline \multicolumn{5}{|c|}{ Detectable viral load } \\
\hline Yes & $23(38.3)$ & $13(31.7)$ & $10(52.6)$ & 0.121 \\
\hline No & $31(51.7)$ & $23(56.1)$ & $8(42.1)$ & 0.313 \\
\hline NA & $6(10.0)$ & $5(12.2)$ & $1(5.3)$ & 0.654 \\
\hline AIDS criteria & $42(70.0)$ & $29(72.5)$ & $13(68.4)$ & 0.747 \\
\hline ART & $53(91.4)$ & $38(95.0)$ & $15(83.3)$ & 0.167 \\
\hline \multicolumn{5}{|l|}{ ART family } \\
\hline NRTI & $46(76.7)$ & $35(85.4)$ & $11(57.9)$ & 0.019 \\
\hline NNRTI & $14(23.3)$ & $7(17.1)$ & $7(36.8)$ & 0.092 \\
\hline PI & $31(51.7)$ & $23(56.1)$ & $8(42.1)$ & 0.313 \\
\hline INSTI & $16(26.7)$ & $11(26.8)$ & $5(26.3)$ & 0.967 \\
\hline Boosted & $24(40.0)$ & $17(41.5)$ & $7(36.8)$ & 0.734 \\
\hline
\end{tabular}

Significant $p$ values in bold

$M S M$ men who have sex with men, IVDU intravenous drug use, $N A$ not available, $A R T$ antiretroviral treatment, $N R T I$ nucleoside reverse transcriptase inhibitors, NNRTI non-nucleoside reverse transcriptase inhibitors, $P I$ protease inhibitors, INSTI integrase inhibitors

\section{Comparison of Cases and Controls}

Table 4 shows the comparison between cases (HIV-infected) and controls (non-HIV-infected). Cases had chronic liver disease more frequently $(p=0.003)$, while controls more commonly had acute leukemia $(p=0.013)$ and HSCT $(p=0.023)$. There was a non-significant trend for cases to receive inappropriate empirical antibiotic treatment (IEAT) $(p=0.206)$, present with shock $(p=0.105)$, and have higher mortality $(p=0.084)$. 
Table 2 Evolution of HIV characteristics over time

\begin{tabular}{|c|c|c|c|c|}
\hline & $1997-2003 n=16(\%)$ & $2004-2010 n=23(\%)$ & $2011-2018 n=21(\%)$ & $p$ value for trend \\
\hline \multicolumn{5}{|l|}{ Risk behavior } \\
\hline MSM & $7(43.8)$ & $9(39.1)$ & $12(57.1)$ & 0.381 \\
\hline Heterosexual & $4(25.0)$ & $10(43.5)$ & $4(19.0)$ & 0.592 \\
\hline IVDU & $2(12.5)$ & $2(8.7)$ & $5(23.8)$ & 0.302 \\
\hline Unknown & $3(18.8)$ & $2(8.7)$ & $0(0)$ & 0.043 \\
\hline \multicolumn{5}{|c|}{ Prior CD4 count } \\
\hline$<100$ & $6(37.5)$ & $4(17.4)$ & $11(52.4)$ & 0.264 \\
\hline $101-200$ & $3(18.8)$ & $8(34.8)$ & $3(14.3)$ & 0.651 \\
\hline $201-350$ & $2(12.5)$ & $5(21.7)$ & $1(4.8)$ & 0.421 \\
\hline$>350$ & $3(18.8)$ & $4(17.4)$ & $3(14.3)$ & 0.714 \\
\hline NA & $2(20.0)$ & $2(16.7)$ & $3(18.8)$ & 0.957 \\
\hline \multicolumn{5}{|c|}{ Detectable viral load } \\
\hline Yes & $9(56.3)$ & $9(39.1)$ & $5(23.8)$ & 0.046 \\
\hline No & $5(31.3)$ & $13(56.5)$ & $13(61.9)$ & 0.076 \\
\hline NA & $2(12.5)$ & $1(4.3)$ & $3(14.3)$ & 0.785 \\
\hline AIDS criteria & $11(68.8)$ & $17(73.9)$ & $14(66.7)$ & 0.640 \\
\hline ART & $13(86.7)$ & $20(90.9)$ & $20(95.2)$ & 0.368 \\
\hline \multicolumn{5}{|l|}{ ART family } \\
\hline NRTI & $13(81.3)$ & $13(56.5)$ & $20(95.2)$ & 0.220 \\
\hline NNRTI & $2(12.5)$ & $8(34.8)$ & $4(19.0)$ & 0.747 \\
\hline PI & $11(68.8)$ & $10(43.5)$ & $10(47.6)$ & 0.240 \\
\hline INSTI & $0(0)$ & $3(13.0)$ & $13(61.9)$ & $<0.001$ \\
\hline Boosted & $4(25)$ & $10(43.5)$ & $10(47.6)$ & 0.181 \\
\hline
\end{tabular}

Significant $p$ values in bold

$M S M$ men who have sex with men, IVDU intravenous drug use, $N A$ not available, $A R T$ antiretroviral treatment, $N R T I$ nucleoside reverse transcriptase inhibitors, NNRTI non-nucleoside reverse transcriptase inhibitors, $P I$ protease inhibitors, INSTI integrase inhibitors

\section{Prognostic Factors in the Case-Control Cohort}

In the univariate analysis of the case-control cohort, diabetes mellitus $(p=0.028)$, myelodysplastic syndrome $(p=0.020)$, solid neoplasm $(p=0.005)$, pulmonary $(p<0.001)$, and abdominal source $(p=0.030)$, candidemia $(p=0.001)$, and shock $(p<0.001)$ were associated with increased mortality. Conversely, Hodgkin's lymphoma $(p=0.030)$ and catheterrelated BSI $(p<0.001)$ were associated with decreased mortality.

Table 5 describes the prognostic factors in the case-control cohort. Factors independently associated with increased mortality were: myelodysplastic syndrome (OR 11.208, CI 
Table 3 Comparison of bloodstream infection episodes in patients with and without HIV infection

\begin{tabular}{|c|c|c|c|}
\hline & HIV $n=60(\%)$ & Non-HIV $n=1695(\%)$ & $p$ value \\
\hline \multicolumn{4}{|c|}{ Demographic characteristics and baseline disease } \\
\hline Median age (IQR) & $49(38-59)$ & $56(43-66)$ & $<0.001$ \\
\hline Male sex & $52(86.7)$ & $966(57.0)$ & $<0.001$ \\
\hline Diabetes mellitus & $5(8.3)$ & $134(7.9)$ & 0.904 \\
\hline COPD & $1(1.7)$ & $68(4.0)$ & 0.729 \\
\hline Chronic liver disease & $9(15)$ & $40(2.4)$ & $<0.001$ \\
\hline Chronic renal failure & $2(3.3)$ & $51(3.0)$ & 0.702 \\
\hline Solid neoplasia & $6(10.0)^{\mathrm{a}}$ & $274(16.2)$ & 0.200 \\
\hline Hematologic malignancy & $57(95.0)$ & $1489(87.8)$ & 0.093 \\
\hline Hematopoietic stem cell transplantation & $1(1.7)$ & $449(26.5)$ & $<0.001$ \\
\hline \multicolumn{4}{|l|}{ Episode characteristics } \\
\hline Central venous catheter & $46(88.5)$ & $1251(89)$ & 0.896 \\
\hline Corticosteroids & $27(45.8)$ & $690(42.5)$ & 0.620 \\
\hline \multicolumn{4}{|l|}{ Bacteremia source } \\
\hline Endogenous/unknown & $27(45.0)$ & $914(53.9)$ & 0.173 \\
\hline Catheter-related & $18(30.0)$ & $410(24.2)$ & 0.303 \\
\hline Pulmonary & $6(10.0)$ & $112(6.6)$ & 0.302 \\
\hline Abdominal & $3(5.0)$ & $46(2.7)$ & 0.233 \\
\hline Shock & $17(28.3)$ & $275(16.3)$ & 0.014 \\
\hline ICU admission & $10(16.7)$ & $121(7.1)$ & 0.006 \\
\hline \multicolumn{4}{|l|}{ Microbiological characteristics } \\
\hline Gram-negative bacilli & $32(53.3)$ & $865(51.0)$ & 0.726 \\
\hline E. coli & $9(15.0)$ & $415(24.5)$ & 0.092 \\
\hline P. aeruginosa & $10(16.7)$ & $212(12.5)$ & 0.341 \\
\hline Klebsiella spp. & $3(5.0)$ & $102(6.2)$ & 1.000 \\
\hline Gram-positive cocci & $24(40.0)$ & $784(46.3)$ & 0.340 \\
\hline CoNS & $11(18.3)$ & $500(29.5)$ & 0.061 \\
\hline Enterococcus spp. & $11(18.3)$ & $155(9.1)$ & 0.017 \\
\hline S. aureus & $4(6.7)$ & $62(3.7)$ & 0.282 \\
\hline S. pneumoniae & $1(1.7)$ & $14(0.8)$ & 0.408 \\
\hline Candidemia & $5(8.3)$ & $67(4.0)$ & 0.093 \\
\hline Polymicrobial & $7(11.7)$ & $151(8.9)$ & 0.463 \\
\hline Outcomes & & & \\
\hline
\end{tabular}


Table 3 continued

\begin{tabular}{lllr}
\hline & HIV $\boldsymbol{n}=\mathbf{6 0}(\%)$ & Non-HIV $\boldsymbol{n}=\mathbf{1 6 9 5}(\%)$ & $\boldsymbol{p}$ value \\
\hline IEAT & $19(31.7)$ & $405(24.4)$ & 0.198 \\
30-day mortality & $19(31.7)$ & $303(18.1)$ & $\mathbf{0 . 0 0 8}$ \\
\hline
\end{tabular}

Significant $p$ values in bold

$I Q R$ interquartile range, $C O P D$ chronic obstructive pulmonary disease, $B S I$ bloodstream infection, $I C U$ intensive care unit, CoNS coagulase-negative staphylococci, IEAT inappropriate empirical antibiotic treatment

${ }^{a}$ Including 3 patients with Kaposi's sarcoma and hematological malignancy

1.775-70.774), solid neoplasm (OR 5.283, CI 1.139-24.513), pulmonary source (OR 11.515, CI 2.504-52.961), abdominal source (OR 72.323, CI 2.752-1900.833), shock (OR 6.477, CI 2.254-18.613), and candidemia (OR 15.297, CI 4.298-54.453). Hodgkin's lymphoma as a baseline disease was protective (OR 0.077, CI 0.006-0.971). The goodness-of-fit of the multivariate model was evaluated using the Hosmer-Lemeshow test (0.439), and the discriminatory power of the score, evaluated by the area under the receiver operating characteristics curve, was 0.826 (95\% CI 0.756-0.897), demonstrating a strong ability to predict mortality at 30 days. HIV was not an independent factor associated with mortality (OR 1.957, 95\% CI 0.708-5.410, $p=0.196$ ).

\section{DISCUSSION}

The current study describes the characteristics of BSI episodes in HIV-infected patients with cancer and febrile neutropenia following chemotherapy compared to patients without HIV infection, and evaluates the risk factors for mortality in this population. The most important findings were: (1) HIV-infected patients with cancer, febrile neutropenia, and BSI are younger, more commonly present chronic liver disease and enterococcal BSI, and undergo HSCT less frequently; (2) HIV-infected patients present with shock more frequently and have a higher mortality; (3) in patients with HIV and cancer, diabetes mellitus and shock are independent risk factors for mortality; (4) in the case-control cohort, independent risk factors for mortality were myelodysplastic syndrome, solid neoplasm, pulmonary source, abdominal source, shock and candidemia, while Hodgkin's lymphoma was protective; and (5) HIV infection by itself was not an independent risk factor associated with mortality.

Patients with HIV and cancer had different demographic and epidemiological characteristics that those patients without HIV. For example, patients with HIV received HSCT less frequently. This could be because most patients with HIV had lymphomas, whereby HSCT is indicated only in cases of relapse after first-line treatment. It is also possible that social problems or drug addiction contraindicated transplant or a discriminatory effect due to HIV status existed.

In this study, most patients with HIV and cancer were men who have sex with men with low prevalence of intravenous drug use. Although the present study evaluates a long period of time (21 years), this is in line with most current series in Western countries [21]. Most patients were on ART; however, $38.3 \%$ of patients had a detectable viral load prior to febrile neutropenia and only $16.7 \%$ had a CD4 count $>350$. Furthermore, $70.0 \%$ met AIDSdefining criteria. A likely explanation for the high rates of detectable viral load and low CD4 counts despite high rates of ART could be that many patients were either late presenters who recently initiated ART and/or had begun treatment at the time of cancer diagnosis. Indeed, mean detectable viral loads were high and time since initiation of ART was mainly brief. Another possible explanation could be low adherence to ART, which is in turn related to a higher likelihood of developing cancer [8]. Unfortunately, we do not have data on 
Table 4 Comparison of cases and controls matched by the main variables

\begin{tabular}{|c|c|c|c|}
\hline & HIV $n=60(\%)$ & Non-HIV $n=120(\%)$ & $p$ value \\
\hline \multicolumn{4}{|c|}{ Demographic characteristics and baseline disease } \\
\hline Median age (IQR) & $49(38-59)$ & $52(39-62)$ & 0.432 \\
\hline Male sex & $52(86.7)$ & $97(80.8)$ & 0.329 \\
\hline Diabetes mellitus & $5(8.3)$ & $7(5.8)$ & 0.526 \\
\hline COPD & $1(1.7)$ & $4(3.3)$ & 0.666 \\
\hline Chronic liver disease & $9(15.0)$ & $3(2.5)$ & 0.003 \\
\hline Chronic renal failure & $2(3.3)$ & $6(5.0)$ & 0.721 \\
\hline Solid neoplasia & $6(10.0)^{\mathrm{a}}$ & $7(6.1)$ & 0.769 \\
\hline Hematologic malignancy & $57(95.0)$ & $113(94.2)$ & 0.309 \\
\hline \multicolumn{4}{|l|}{ Type of hematologic malignancy } \\
\hline Acute leukemia & $2(3.3)$ & $19(16)$ & 0.013 \\
\hline MDS & $3(5.0)$ & $5(4.2)$ & 1.000 \\
\hline Multiple myeloma & $2(3.3)$ & $6(5.0)$ & 0.720 \\
\hline NHL & $41(68.3)$ & $68(57.1)$ & 0.148 \\
\hline $\mathrm{HL}$ & $9(15)$ & $13(10.9)$ & 0.433 \\
\hline Hematopoietic stem cell transplantation & $1(1.7)$ & $15(12.5)$ & 0.023 \\
\hline \multicolumn{4}{|l|}{ Episode characteristics } \\
\hline Corticosteroids & $27(45.8)$ & $60(50.0)$ & 0.524 \\
\hline \multicolumn{4}{|l|}{ Bacteremia source } \\
\hline Endogenous/unknown & $27(45.0)$ & $62(51.7)$ & 0.399 \\
\hline Catheter-related & $18(30.0)$ & $33(27.5)$ & 0.726 \\
\hline Pulmonary & $6(10.0)$ & $8(6.7)$ & 0.431 \\
\hline Abdominal & $3(5.0)$ & $3(2.5)$ & 0.402 \\
\hline Skin/soft tissues & $3(5.0)$ & $6(5.0)$ & 1.000 \\
\hline Urinary & $1(1.7)$ & $6(5.0)$ & 0.427 \\
\hline Mucositis & $2(3.3)$ & $2(1.7)$ & 0.602 \\
\hline Neutropenia $<100$ & $40(66.7)$ & $79(69.9)$ & 0.661 \\
\hline Shock & $17(28.3)$ & $21(17.8)$ & 0.105 \\
\hline ICU admission & $10(16.7)$ & $8(6.7)$ & 0.035 \\
\hline \multicolumn{4}{|l|}{ Microbiological characteristics } \\
\hline Gram-negative bacilli & $32(53.3)$ & $68(56.7)$ & 0.671 \\
\hline E. coli & $9(15.0)$ & $22(18.3)$ & 0.577 \\
\hline P. aeruginosa & $10(16.7)$ & $17(14.2)$ & 0.658 \\
\hline
\end{tabular}


Table 4 continued

\begin{tabular}{|c|c|c|c|}
\hline & HIV $n=60(\%)$ & Non-HIV $n=120(\%)$ & $p$ value \\
\hline Klebsiella spp. & $3(5.0)$ & $10(8.3)$ & 0.548 \\
\hline Pseudomonas spp. (not aeruginosa) & $3(5.0)$ & $5(4.2)$ & 1.000 \\
\hline Enterobacter spp. & $1(1.7)$ & $6(5.0)$ & 0.427 \\
\hline Fusobacterium spp. & $1(1.7)$ & $3(2.5)$ & 1.000 \\
\hline S. maltophilia & $1(1.7)$ & $3(2.5)$ & 1.000 \\
\hline Proteus spp. & $1(1.7)$ & $1(0.8)$ & 1.000 \\
\hline Serratia spp. & $1(1.7)$ & $1(0.8)$ & 1.000 \\
\hline Bacteroides spp. & $1(1.7)$ & $1(0.8)$ & 1.000 \\
\hline Other $\mathrm{GNB}^{\mathrm{b}}$ & $1(1.7)$ & $2(1.7)$ & 1.000 \\
\hline Gram-positive cocci & $24(40.0)$ & $52(43.3)$ & 0.670 \\
\hline CoNS & $11(18.3)$ & $24(20.0)$ & 0.790 \\
\hline Enterococcus spp. & $11(18.3)$ & $14(11.7)$ & 0.223 \\
\hline S. aureus & $4(6.7)$ & $8(6.7)$ & 1.000 \\
\hline Streptococcus spp. & $2(3.3)$ & $6(5.0)$ & 0.721 \\
\hline Other Gram-positive cocci ${ }^{\mathrm{c}}$ & $0(0)$ & $2(1.7)$ & 0.553 \\
\hline Candidemia & $5(8.3)$ & $11(9.2)$ & 0.853 \\
\hline Polymicrobial & $7(11.7)$ & $12(10.0)$ & 0.732 \\
\hline \multicolumn{4}{|l|}{ Outcomes } \\
\hline IEAT & $19(31.7)$ & $27(22.9)$ & 0.206 \\
\hline 30-day mortality & $19(31.7)$ & $24(20.0)$ & 0.084 \\
\hline
\end{tabular}

Significant $p$ values in bold

$I Q R$ interquartile range, COPD chronic obstructive pulmonary disease, $M D S$ myelodysplastic syndrome, NHL NonHodgkin's lymphoma, HL Hodgkin's lymphoma, BSI bloodstream infection, ICU intensive care unit, CoNS coagulasenegative staphylococci, IEAT inappropriate empirical antibiotic treatment

a Including 3 patients with Kaposi's sarcoma and hematological malignancy

b Including 1 Acinetobacter spp., 1 Citrobacter spp., and 1 Clostridium spp.

c Including 1 Leuconostoc spp., and 1 Gemella haemolysans

adherence of such patients prior to febrile neutropenia. Finally, the percentage of patients with a detectable viral load decreased over time, probably following the overall, gradually improved management of patients with HIV.

Protease inhibitor-based ART was the most commonly used regimen. Protease inhibitors are potent inhibitors of the cytochrome P450 $3 \mathrm{~A} 4$, and frequently cause problematic drug- drug interactions with several chemotherapeutic and immunosuppressive agents [22]. This can lead to increased toxicity and a potential delay in chemotherapy treatments. In this setting, non-boosted integrase inhibitors are increasingly being used due to a more favorable drug-drug interaction profile and better tolerability [23, 24], as observed in our cohort. Although this may have impact on the 
Table 5 Prognostic factors in the case-control cohort

\begin{tabular}{llr}
\hline Risk factor & Odds ratio $(\mathbf{9 5 \%}$ confidence interval) & $\boldsymbol{p}$ value \\
\hline Hodgkin's lymphoma & $0.077(0.006-0.971)$ & 0.047 \\
Myelodysplastic syndrome & $11.208(1.775-70.774)$ & 0.010 \\
Solid neoplasia & $5.283(1.139-24.513)$ & 0.034 \\
Pulmonary source & $11.515(2.504-52.961)$ & 0.002 \\
Abdominal source & $72.323(2.752-1900.833)$ & 0.010 \\
Shock & $6.477(2.254-18.613)$ & 0.001 \\
Candidemia & $15.297(4.298-54.453)$ & $<0.001$ \\
HIV-infection & $1.957(0.708-5.410)$ & 0.196 \\
\hline
\end{tabular}

Adjusted for: chronic liver disease, diabetes mellitus, chronic renal failure, HIV, corticosteroid use, catheter-related source, inappropriate empirical antibiotic treatment, coagulase-negative staphylococci bacteremia, S. pneumoniae bacteremia, intensive care unit requirement

outcomes of patients with HIV receiving chemotherapy, we found no differences regarding ART regimen, particularly in the setting of febrile neutropenic BSI.

In this study, patients with HIV and cancer experienced higher mortality than those without HIV. Several factors may explain this finding. In the overall cohort, patients with HIV more commonly presented some features associated with higher mortality in univariate analysis (besides HIV itself), e.g., chronic liver disease, enterococcal infection, IEAT, and shock. In the case-control cohort, despite matching for age, sex, baseline disease, and etiological microorganism, there was still a trend for patients with HIV to have higher mortality, and present with higher chronic liver disease and higher ICU requirement. It remains unclear why patients with HIV who develop BSI in the context of febrile neutropenia present with higher enterococcal infection, shock, and ICU requirement. As previously mentioned, the drug-drug interaction problem could have had an influence on prognosis. Co-infection rates with HCV and/or HBV in the HIV population was high, and this variable could have also impacted mortality, although this variable was not available in patients without HIV. It could also be possible that patients with HIV were a more vulnerable population after previous opportunistic infections or as a result of a more fragile baseline status. In fact, enterococcal infection has classically been associated with fragile patients, and reports of an increased prevalence in the HIV population already exist, although precise drivers are unknown $[25,26]$. Lastly, defects in innate immunity and neutrophil function have been described in patients with HIV, comprising lower bactericidal ability, malfunctioning degranulation, and poor phagocytosis and chemotaxis [27]. This could have played a deleterious role in these patients; however, knowledge about such pathways in neutropenic patients with HIV is scarce.

Low CD4 cell count has been previously associated with prolonged febrile neutropenia and increased mortality due to infection following chemotherapy [28]. However, in this study, we describe the characteristics of patients who already present a BSI in the context of febrile neutropenia following chemotherapy, which is when many also have profound lymphopenia. In this setting, however, prior CD4 count was not found to be an independent predictor of mortality.

The strengths of this study are the large number of febrile neutropenic cancer patients with BSI included; the prospective collection of the data; the comprehensive clinical and microbiological data gathered; and the matched case-control comparison. Additionally, to our best knowledge, this is the first study to evaluate 
the characteristics and outcomes of patients with HIV and cancer who develop BSI and febrile neutropenia.

There are, nonetheless, some limitations that should be acknowledged. The number of patients with HIV was relatively low, especially when considering the extended length of the study period. Continuous variations occur in the characteristics and treatments of patients with HIV, and larger, up-to-date studies are needed. Secondly, this study was conducted in a single center, and microbiological epidemiology varies significantly in different geographical contexts. Lastly, cases and controls were matched by several characteristics (including etiology) in an attempt to assess the true impact of HIV; however, this precluded any evaluation of potentially different etiological microorganisms in otherwise similar patients.

\section{CONCLUSIONS}

In conclusion, in comparison to controls, overall HIV-infected patients with cancer who develop febrile neutropenia and a BSI have different epidemiological and clinical profiles, and experience higher mortality. However, in the case-control study, HIV infection by itself was not associated with mortality.

\section{ACKNOWLEDGEMENTS}

We would like to thank RIS (Red de Investigación de SIDA) and the participants of the study.

Funding. This study has been co-funded by the European Regional Development Fund (EDRD). PP-A [CM18/00132], NG-P [FI19/ 00133], EM-G [PI18/01061] and CG-V [FIS PI18/ 01061] have received research grants from the Ministerio de Sanidad y Consumo, Instituto de Salud Carlos III. JMM received a personal 80:20 research grant from Institut d'Investigacions Biomèdiques August Pi i Sunyer (IDIBAPS), Barcelona, Spain, during 2017-21. No funding bodies had any role in study design, data collection and analysis, decision to publish, or preparation of the manuscript. No funding or sponsorship was received for the publication of this article.

Authorship. All named authors meet the International Committee of Medical Journal Editors (ICMJE) criteria for authorship for this article, take responsibility for the integrity of the work as a whole, and have given their approval for this version to be published.

Author Contributions. PP-A, JA, JMM, CG$\mathrm{V}$ : Literature search, study design, data collection, data analysis, data interpretation, writing, and decision to submit. PP-A: Statistical analyses. All authors: writing-review and editing. PPA, JA, AS, JMM and CG-V: Data interpretation, writing and decision to submit. The corresponding author attests that all listed authors meet authorship criteria and that no others meeting the criteria have been omitted.

English Language/Syntax Assistance. We would like to thank the contributions made by Anthony Armenta in the form of his corrections to the English language/syntax of this publication. His work was funded with private resources from the Department of Infectious Diseases of the Hospital Clínic de Barcelona.

Prior Presentation. The results of this manuscript were partially sent and accepted as a poster at the finally cancelled 30th ECCMID 2020 and are included in the ECCMID 2020 Abstract Book (Abstract number: 3096). Additionally, this manuscript is part of the final work of the master's degree in AIDS at the University of Barcelona.

Disclosures. Pedro Puerta-Alcalde has received honoraria for talks on behalf of Gilead Science, Merck Sharp and Dohme and ViiV Healthcare. Carolina Garcia-Vidal has received honoraria for talks on behalf of Gilead Science, Merck Sharp and Dohme, Pfizer, Jannsen, Novartis, Lilly and a grant support from Gilead Science and Merck Sharp and Dohme. Alex Soriano has received honoraria for talks on behalf of Merck Sharp and Dohme, Pfizer, 
Novartis, Angellini, and a grant support from Pfizer. Alex Soriano is also the Co-Editor-inChief of this journal. Josep Mensa has received honoraria for talks on behalf of Merck Sharp and Dohme, Pfizer, Novartis and Angellini. Juan Ambrosioni has received honoraria for talks, has participated in advisory boards and/or has received funding for research from $\mathrm{ViiV}$ Healthcare, Gilead Sciences and Janssen Pharmaceuticals, of which all are outside the current work. Juan Ambrosioni is also a member of the journal's Editorial board. Mariana Chumbita, Marta Hernández-Meneses, Nicole Garcia-Pouton, Celia Cardozo, Estela Moreno-Garcia, Francesc Marco, Montserrat Rovira, Jordi Esteve, Jose A. Martínez, Felipe García, Josep Mallolas and José M. Miró have nothing to disclose.

Compliance with Ethics Guidelines. This study was performed in accordance with the Helsinki Declaration of 1964 and its later amendments, and followed privacy laws regarding active anonymity. This study was approved by the Ethics Committee Board of our institution (Comité de Ética de la Investigación con medicamentos, Hospital Clínic de Barcelona) with the following approval verdict: $\mathrm{HCB} /$ 2019/0764. Informed consent was waived due to the retrospective nature of the study.

Data Availability. The datasets generated during and analyzed during the current study are available from the corresponding author on reasonable request.

Open Access. This article is licensed under a Creative Commons Attribution-NonCommercial 4.0 International License, which permits any non-commercial use, sharing, adaptation, distribution and reproduction in any medium or format, as long as you give appropriate credit to the original author(s) and the source, provide a link to the Creative Commons licence, and indicate if changes were made. The images or other third party material in this article are included in the article's Creative Commons licence, unless indicated otherwise in a credit line to the material. If material is not included in the article's Creative Commons licence and your intended use is not permitted by statutory regulation or exceeds the permitted use, you will need to obtain permission directly from the copyright holder. To view a copy of this licence, visit http://creativecommons.org/licenses/by$\mathrm{nc} / 4.0 /$.

\section{REFERENCES}

1. Klastersky J, Ameye L, Maertens J, Georgala A, Muanza F, Aoun M, et al. Bacteraemia in febrile neutropenic cancer patients. Int $\mathrm{J}$ Antimicrob Agents 2007; 30:51-9. Available from: http://www. ncbi.nlm.nih.gov/pubmed/17689933

2. Nørgaard M, Larsson H, Pedersen G, Schønheyder HC, Sørensen HT. Risk of bacteraemia and mortality in patients with haematological malignancies. Clin Microbiol Infect. 2006;12:217-23 ((European Society of Clinical Infectious Diseases)).

3. Gudiol C, Tubau F, Calatayud L, Garcia-Vidal C, Cisnal M, Sanchez-Ortega I, et al. Bacteraemia due to multidrug-resistant Gram-negative bacilli in cancer patients: risk factors, antibiotic therapy and outcomes. J Antimicrob Chemother 2011; 66: 657-63. Available from: http://www.ncbi.nlm.nih. gov/pubmed/21193475

4. Averbuch D, Tridello G, Hoek J, Mikulska M, Akan H, Yanez San Segundo L, et al. Antimicrobial resistance in Gram-negative rods causing bacteremia in hematopoietic stem cell transplant patients: intercontinental prospective study of Infectious Diseases Working Party of the European Bone Marrow Transplantation group. Clin Infect Dis. 2017;65(11):1819-28.

5. Garcia-Vidal C, Cardozo-Espinola C, Puerta-Alcalde P, Marco F, Tellez A, Agü Ero D, et al. Risk factors for mortality in patients with acute leukemia and bloodstream infections in the era of multiresistance. PLoS One 2018; 13:1-12. Available from: http://journals.plos.org/plosone/article/file?id= https://doi.org/10.1371/journal.pone. 0199531\&type $=$ printable

6. Martinez-Nadal G, Puerta-Alcalde P, Gudiol C, Cardozo C, Albasanz-Puig A, Marco F et al. Inappropriate empirical antibiotic treatment in highrisk neutropenic patients with bacteremia in the era of multidrug resistance. Clin Infect Dis 2019; Available from: https://academic.oup.com/cid/ advance-article/. Doi: https://doi.org/10.1093/cid/ ciz319/5479518

7. Goedert JJ, Coté TR, Virgo P, Scoppa SM, Kingma DW, Gail MH et al. Spectrum of AIDS-associated malignant disorders. Lancet 1998; 351:1833-9. 
Available from: http://www.ncbi.nlm.nih.gov/ pubmed/9652666

8. Frisch M, Biggar RJ, Engels EA, Goedert JJ, AIDSCancer Match Registry Study Group. Association of cancer with AIDS-related immunosuppression in adults. JAMA 2001; 285:1736-45. Available from: http://www.ncbi.nlm.nih.gov/pubmed/11277828

9. Centers for Disease Control and Prevention. HIV Surveillance Report, 2017; 29

10. Palella FJ, Delaney KM, Moorman AC, Loveless MO, Fuhrer J, Satten GA et al. Declining morbidity and mortality among patients with advanced human immunodeficiency virus infection. N Engl J Med. 1998; 338:853-60. Available from: http://www. ncbi.nlm.nih.gov/pubmed/9516219

11. Trickey A, May MT, Vehreschild J-J, Obel N, Gill MJ, Crane HM et al. Survival of HIV-positive patients starting antiretroviral therapy between 1996 and 2013: a collaborative analysis of cohort studies. Lancet HIV. 2017; 4:e349-56. Available from: http://www.ncbi.nlm.nih.gov/pubmed/28501495

12. Cobucci RNO, Lima PH, de Souza PC, Costa VV, Cornetta $\mathrm{M}$ da $\mathrm{C}$ de $\mathrm{M}$, Fernandes JV, et al. Assessing the impact of HAART on the incidence of defining and non-defining AIDS cancers among patients with HIV/AIDS: a systematic review. J Infect Public Health. 2015; 8:1-10. Available from: https://linkinghub.elsevier.com/retrieve/pii/ S1876034114001415

13. Engels EA, Biggar RJ, Hall HI, Cross H, Crutchfield $A$, Finch JL et al. Cancer risk in people infected with human immunodeficiency virus in the United States. Int J Cancer 2008; 123:187-94. Available from: http://www.ncbi.nlm.nih.gov/pubmed/ 18435450

14. Robbins HA, Shiels MS, Pfeiffer RM, Engels EA. Epidemiologic contributions to recent cancer trends among HIV-infected people in the United States. AIDS 2014; 28:881-90. Available from: https://insights.ovid.com/crossref?an=00002030201403270-00010

15. Grulich AE, van Leeuwen MT, Falster MO, Vajdic CM. Incidence of cancers in people with HIV/AIDS compared with immunosuppressed transplant recipients: a meta-analysis. Lancet 2007; 370:59-67. Available from: https://linkinghub.elsevier.com/ retrieve/pii/S0140673607610502

16. Coghill AE, Pfeiffer RM, Shiels MS, Engels EA. Excess mortality among HIV-infected individuals with cancer in the United States. Cancer Epidemiol Biomark Prev 2017; 26:1027-33. Available from: http://www.ncbi.nlm.nih.gov/pubmed/28619832
17. Freifeld AG, Bow EJ, Sepkowitz KA, Boeckh MJ, Ito JI, Mullen CA et al. Clinical practice guideline for the use of antimicrobial agents in neutropenic patients with cancer: 2010 Update by the Infectious Diseases Society of America. Clin Infect Dis 2011; 52:352-3. Oxford University Press. Available from: http://www.ncbi.nlm.nih.gov/pubmed/21205990

18. Viasus D, Puerta-Alcalde P, Cardozo C, Suárez-Lledó M, Rodríguez-Núñez O, Morata L, et al. Predictors of multidrug-resistant Pseudomonas aeruginosa in neutropenic patients with bloodstream infection. Clin Microbiol Infect. 2020;26:345-50 ((Elsevier B. V.)).

19. Puerta-Alcalde P, Cardozo C, Marco F, Suárez-Lledó M, Moreno E, Morata L, et al. Changing epidemiology of bloodstream infection in a 25-years hematopoietic stem cell transplant program: current challenges and pitfalls on empiric antibiotic treatment impacting outcomes. Bone Marrow Transplant. 2020;55:603-12 ((Springer Nature)).

20. Marschall J, Mermel LA, Fakih M, Hadaway L, Kallen A, O'Grady NP et al. Strategies to prevent central line-associated bloodstream infections in acute care hospitals: 2014 Update. Infect Control Hosp Epidemiol. 2014; 35:753-71. Cambridge University Press, Cambridge. Available from: https://pubmed. ncbi.nlm.nih.gov/24915204/

21. Singh S, Song R, Johnson AS, McCray E, Hall HI. HIV incidence, prevalence, and undiagnosed infections in US Men who have sex with men. Ann Intern Med. 2018;168:684-94 ((American College of Physicians)).

22. Mounier N, Katlama C, Costagliola D, Chichmanian RM, Spano JP. Drug interactions between antineoplastic and antiretroviral therapies: Implications and management for clinical practice. Crit Rev Oncol Hematol. 2009;1:10-20.

23. Casado JL, Machuca I, Bañón S, Moreno A, Moltó J, Rodriguez MA. Raltegravir plus two nucleoside analogues as combination antiretroviral therapy in HIV-infected patients who require cancer chemotherapy. Antivir Ther. 2015;20:773-7 ((International Medical Press Ltd)).

24. Torres HA, Rallapalli V, Saxena A, Granwehr BP, Viola GM, Ariza-Heredia E, et al. Efficacy and safety of antiretrovirals in HIV-infected patients with cancer. Clin Microbiol Infect. 2014;20:O672-9 ((Blackwell Publishing Ltd)).

25. Schönwald S, Begovac J, Skerk V. Urinary tract infections in HIV disease. Int J Antimicrob Agents. 1999;1:309-11.

26. Declercq S, De Munter P, Derdelinckx I, Verhaegen $\mathrm{J}$, Peetermans WE, Vanderschueren $\mathrm{S}$, et al. 
Characteristics, causes, and outcome of 54 episodes of bloodstream infections in a cohort of HIV patients. Infect Dis (Auckl). 2015; 47:611-7. Taylor and Francis, London. Available from: http://www. ncbi.nlm.nih.gov/pubmed/25875395

27. Shi $X$, Sims MD, Hanna MM, Xie M, Gulick PG, Zheng Y-H, et al. Neutropenia during HIV Infection: adverse consequences and remedies. Int Rev Immunol. 2014; 33:511-36. Available from: http:// www.tandfonline.com/doi/full/. Doi: https://doi. org/10.3109/08830185.2014.893301

28. Borg C, Ray-Coquard I, Philip I, Clapisson G, Bendriss-Vermare N, Menetrier-Caux C, et al. CD4 lymphopenia as a risk factor for febrile neutropenia and early death after cytotoxic chemotherapy in adult patients with cancer. Cancer. 2004;101: 2675-80 (Wiley, New York). 